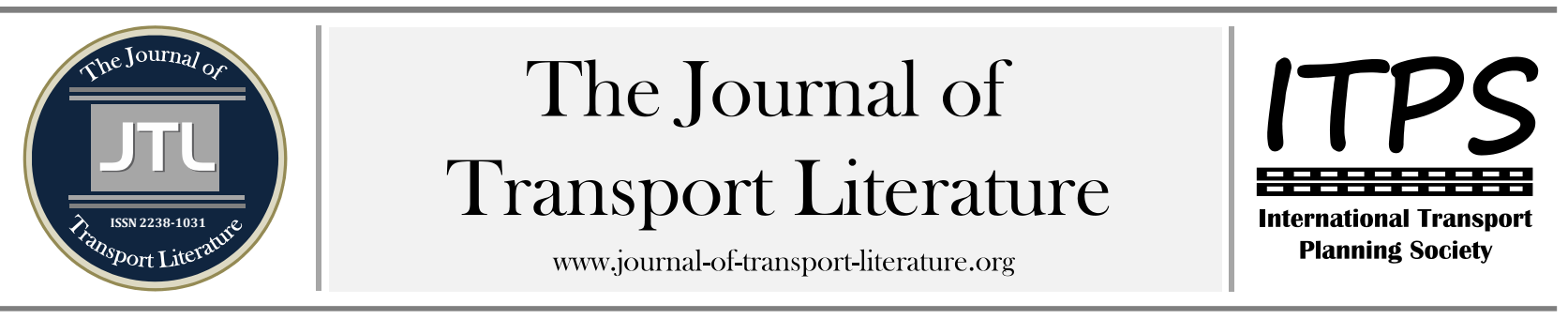

\title{
Development of a feasibility model for a High Speed Rail (HSR) line project
}

\author{
Reinaldo C. Garcia+; Aline Goulart; Thais da C. Veiga; Luiza V. da Cunha; Marcos Vilarindo \\ Universidade de Brasília - UnB, Brasília, Brasil.
}

\section{Article Info}

Keywords:

high speed rail

feasibility

risk

project

Submitted 9 Apr 2015;

received in revised form 8 Aug 2015

accepted 31 Aug 2015

Licensed under

Creative Commons

CC-BY 3.0 BR.

\section{Abstract}

The building costs of a High Speed Rail line project besides its acquisition, operation and maintenance ones, are very high making it an expensive option of transportation. The implementation of a HSR project must then be evaluated, determining its costs and revenues, in order to justify its viability. This research proposes a model to evaluate the feasibility of a HSR line. The model considers the cases where the demand and the costs have uncertainties, assuming also that the initial evaluated demand can be overestimated. A detailed explanation of the proposed model is given and empirical results for the Brazilian HSR project are discussed. The results show that such a project is a very risky one, and it must be carefully discussed before it becomes a reality.

+ Corresponding author. Departamento de Engenharia Industrial, Faculdade de Tecnologia, Universidade de Brasília - UnB, Brasília, DF, 70910-900, Brasil. E-mail address: rcgar@yahoo.com.

\section{Introduction}

Investing in High Speed Rail (HSR) line requests high speed infrastructure requiring, in general, that new dedicated tracks be built at a cost substantially higher than a conventional rail line. Despite its very high costs, this mode of transportation has not only been expanded but also been considered by countries which have not already implemented it.

HSR projects have been developed mainly in Europe and Asia. Nevertheless, other countries are also considering the investment in HSR lines, aiming to change modal split in passenger transport and to reduce congestion, accidents and environmental externalities, among other goals. Particularly, European member countries have their HSR investment projects financially supported by the European Union (de Rus, 2012).

The implementation of a High Speed Rail line in Brazil has been encouraged and financially supported by the Brazilian Federal Government. Even though there is no HSR line in Brazil, the HSR project has been seen by the Brazilian Federal Government as a technological breakthrough, besides being considered a solution to other transport modes including road and airports.

The economics benefits of HSR investment and the opportunity of investing public funds to its development are considered imprecise due, mainly, to the uncertainties in the infrastructure costs and the demand growth for this mode of transportation (Gramlich, 1994). Therefore, investing in HSR must be a central planning decision even tough the decisions to build them are taken without any clear overall plan (Vickerman, 1997). The economic viability of investments in HSR rail infrastructure projects to change modal split is not also guaranteed (Sichelschmidt, 1999).

The rationale for the investment decisions lately in HSR projects has included not only the usual microeconomic approach applied in project evaluation but also strategic and political arguments or regional development objectives. In Europe, the economic appraisal of recent HSR projects include cost-benefit analysis, required by the European Commission, and political and strategic issues related to the regions to be served by the HSR lines.

The HSR technology is particularly popular in the European Union (European Commission - EC, 2001a). In 2001, the EC launched one of its transportation policy called "revitalizing the railways". This EC railway policy aimed to introduce competition in the railway industry and to give priority to public investment in the rail network. Nevertheless, the implementation of a HSR line by countries like Brazil can be politically very attractive, as it can belong to a selected number of countries owning this type of transportation system.

The attraction of building a HSR line has its own risks due to the economics involved when deciding to implement it, as already mentioned. Furthermore, the main economic problem to build an HSR line is whether the social benefits are high enough to compensate the infrastructure and operating costs of this new transport alternative (de Rus, 2012). Other relevant alternatives should also be examined and compared with the investment in HSR.

HSR competes with air and road transport within some very specific distances and it is also considered as a substitute of feeder air services to main hub airports (Banister and Givoni, 2006). The construction of HSR lines can have an increase in trip comfort and in generation of new trips, and reduction in congestion and delays in roads and airports. The 
implementation of HSR line has also released of needed capacity the airports and the conventional rail lines having also wider economic benefits like higher standard of living in the less developed regions (de Rus, 2012).

The economics justification for new investment in HSR is stronger where there exists a potential market for travel within 200-800 km but especially in the range of 300-600 km. The benefits outside this range diminish because the social benefits below $200 \mathrm{~km}$ are quite low and it is difficult to compete with air transport above the range of $800 \mathrm{~km}$. The economics benefits of the construction of new HSR are also very sensitive to the volume of the evaluated demand.

Cities with high population densities along the corridor mean more users sharing the fixed costs of capacity. Nevertheless, high density urban areas mean higher construction costs. The construction costs of a $100 \mathrm{~km}$ high speed railway line (speed above $250 \mathrm{~km} /$ hour) changes dramatically depending on geographic conditions and the crossing of urban areas. In Europe, the construction costs can go from $€ 1,785$ million to $€ 2,921$ million in Italy and, from $€ 625$ million to € 1,334 million in France (Barrón de Angoiti, 2004). A conservative standard average value for the construction of a $100 \mathrm{~km}$ HSR line could be $€ 1,200$ million.

This paper focuses in the implementation of a model to determine the viability of a HSR line. To illustrate the model, real values of construction and maintenance costs, and of the evaluated demand for a Brazilian HSR line are used to determine the feasibility of the Brazilian HSR project.

The paper is organized as follows. Section 2 presents the model used to analyze a HSR project, showing the key elements to be taken into consideration for its economic evaluation. Section 3 describes the values used in our calculations, and the results obtained applying the developed model for the Brazilian HSR line. Finally, section 4 presents the conclusions.

\section{The feasibility Model for a HSR line}

Consider the case of a project consisting of the construction and the operation of a new High Speed Railway line. It is assumed that this project has a life span of $\mathrm{T}$ years, where $\mathrm{T}=40$ years. The construction firm builds the rail infrastructure and superstructure, and the operator buys the mobile equipment during some initial period, which will be considered as the year of reference $(t=0)$ and after when depreciation requires replacement. From $t=0$ until $t=T$, the railway operator charges a regulated fare $\mathrm{p}$ which, for this research, will change yearly according to the inflation rate, assumed to be stochastic. Furthermore, each year the HSR line receives Q users, assumed to change randomly every year during the life of the project.

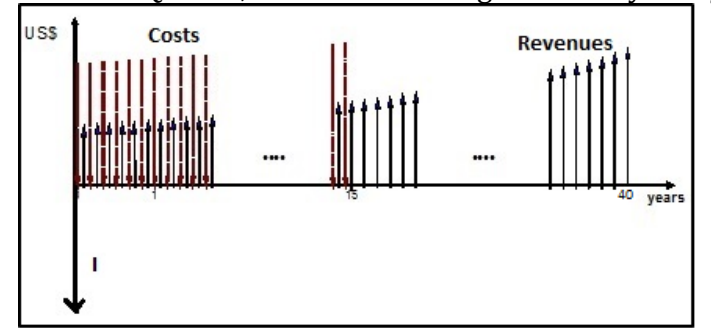

Figure 1 - Graphical depiction of the initial Investment (I), costs and revenues for the HSR line (T=40 years).

Total infrastructure costs are equal to $I$, evaluated in constant terms in the year $t=0$. During the life of the project, the operator incurs into some annual costs of maintaining and operating the rail track, stations, signaling and other fixed plants, besides the operating costs of labor and energy consumed in train operation. The revenues obtained are associated with the fares, $\mathrm{p}$, paid by the passengers, $\mathrm{Q}$. The procedure associated with the costs and revenues associated with the HSR line is depicted in Fig. 1.

\subsection{Uncertainty in the Costs and in the evaluated Demand}

One can extract the growth of the costs and the demand for a transportation mode looking at, for instance, the historical data set for the specific mode. The yearly costs and demand growths are, usually, not constant ones. Therefore, for this research, the costs and the demand have a stochastic variation where their uncertainties are modelled according to a Wiener process:

$$
d s=\mu d t+\sigma d z
$$

where $\mu$ represents the drift and $\sigma$ the volatility of the growth, respectively (Hull, 2005).

The following costs have been considered: infrastructure (rail lines, signing, telecommunication), maintenance (rail lines, bridges, tunnels), labor and, complementary costs (marketing, office utilities). A representative behavior of Eq. (1) is shown in Fig. 2 where 5 trajectories of the simulation are presented for a case where the initial demand is about 3.2 million passengers per year. The Variation of the demand, given in Fig. 2, assume a yearly drift of $5 \%(\mu)$ and a yearly volatility of $2.5 \%(\sigma)$, for the demand.

In the previous published work about the case study to be presented in this paper, the Brazilian HSR Project, there was no uncertainty included either in the demand or in the costs (Halcrow-Sinergia Consortium, July 2009). The next section presents also the possibility of the evaluated initial demand to be overstated.

\subsection{The Overestimation of the Demand}

One of the main problems when evaluating the feasibility of infrastructure projects such as a HSR line is the overestimation of the demand, in order to make it a profitable project. Recently, the discussion related to the feasibility of the HSR project in California (USA), for instance, has had its own difficulties due to the evaluation of the demand (ITS - UC at Berkeley, 2010).

The Final Report analyzing the California HSR project prepared at the request of the California Senate Transportation and Housing Committee was submitted to the California High Speed Rail Authority. In the executive summary of the California Final report, it was stated that the demand forecasts likely misstated the demand (and thus profitability) of the proposed California HSR (ITS - UC at Berkeley, 2010). 


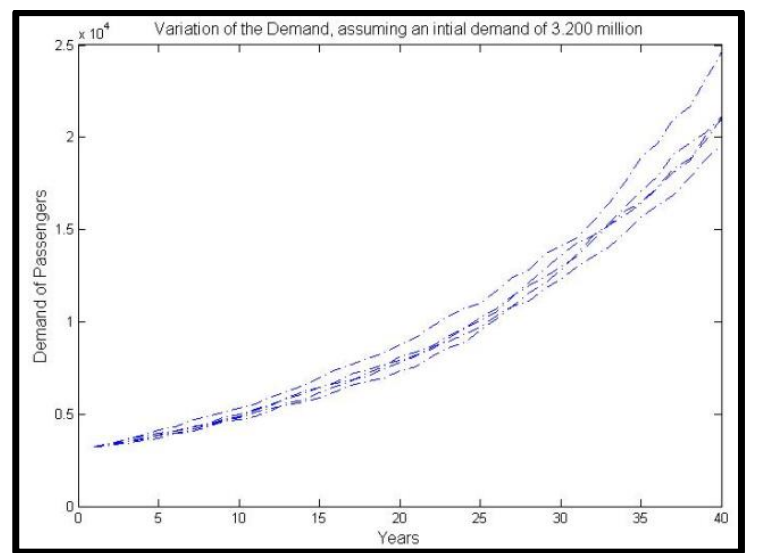

Figure 2 - Variation of the demand, assuming a yearly drift of $5 \%(\mu)$ and a yearly volatility of $2.5 \%(\sigma)$.

In this research, the demand applied for the case study, as input for the proposed model, is given by a study done for the Brazilian HSR project (Halcrow-Sinergia Consortium, 2009). Therefore, when trying to implement the possibility of the evaluated demand be overstated, this work multiplies the initial demand by a factor, $\mathrm{f}$, as given in Eq. 2:

$$
D(t)=f * \text { Demand }_{\text {initial }} \text { for } t=1 \text { (2) }
$$

This multiplying factor, $\mathrm{f}$, can have values of 0.6 or, 0.8 , for instance, meaning the initial real demand, $D(1)$, is $60 \%$ or, $80 \%$ of the given initial demand. The evaluation of the future demands, $D(t)$, will then be based in the initial real demand given by $D(1)$. Applying Eq. 2, as it is done in this work, minimizes the problem of having overstated the initial demand when obtaining the revenues associated with the charged fares.

\subsection{The proposed feasibility model}

This research's goal is to determine the feasibility of a HSR line project by the point of view of the investor. Therefore, possible benefits like environmental and social ones are not considered. The model evaluates the demand, $D(t)$, and the costs, $C(t)$, assuming their stochasticities for every year, t, given by Eq. (1). A concession period of T (40) years for the HSR line is assumed. The total yearly costs for each year $t, C(t)$, are obtained summing up all the costs of infrastructure, maintenance, labor and, complementary costs for every year, where it is assumed a yearly growth rate for these costs given by the inflation rate which is stochastic. The inflation rate is assumed to have a drift of $5 \%$ and a volatility of $2.5 \%$.

In order to obtain the revenues, one must first obtain the fare for each OD (Origin-Destination) pair. The fare for each OD pair is obtained multiplying the OD distance matrix by the evaluated anual fare per distance. The anual fare also increases every year according to the inflation rate. Finally, the yearly revenues for each year $t, R(t)$, are evaluated summing up all the OD revenues obtained when multiplying the given OD demand matrix by the evaluated OD pair fare for every year. The Net Presente Value (NPV) for the Project is then calculated applying Eq. (3):

$\mathrm{NPV}=-I+\sum_{t=1}^{40}[\mathrm{R}(t)-C(t)] /(1+d)^{t-1}$

In the proposed model, the discount rate $\mathrm{d}$ in Eq. (3), is assumed to be $11 \%$. The robustness of the model resides in the fact that the randomness of the demand and its possibly overestimation imply more realistic revenues. The algorithm presented next describes the implemented model:

Algorithm

i) Data Input: - Inital $O D$ pair Demand and, initital Costs, $D(1)$. and $C(1)$.

- Fare per Kilometer and $O D$ pair Distance.

ii) Applied Cases: - Uncertainty for the Demand and the Costs growths.

- Demand overestimation.

iii) Revenues and Costs determination: - Evaluate the yearly Costs: $C(t)$, for $\mathrm{t}=1 \ldots 40$.

- Evaluate the yearly revenues: $R(t)=$ fare $_{t} * D(t)$. , for $t=1, \ldots, 40$.

(assuming a yearly growth of $5 \%$ for the fare and the costs due to the inflation rate, with a volatility of $2.5 \%$ ).

iv) Determination of the Project feasiblity: Net Present Value - NPV

$\mathrm{NPV}=-I+\sum_{t=1}^{40}[R(t)-C(t)] /(1+d)^{t-1}$

where,$I$ is the initial infrastructure investment for the Project and, $d$ is the discount rate.

\section{Case Study - The Brazilian HSR line project}

The case study considered in this study is the High Speed Rail (HSR) line to be built in Brazil connecting the cities of Rio de Janeiro (7 million people) and São Paulo (20 million people). The Brazilian Federal Government (FG) considered the HSR line project to be a flagship project for the Brazilian Olympic Games to be held in 2016 in the city of Rio de Janeiro. The total cost for the project is estimated to be between US\$ 17 billion and US\$ 25 billion but some private sector estimates suggest that the cost could go up to US\$ 40 billion.

The cities to be served by the Brazilian HSR line include Campinas - CAM, Viracopos - VR (Campinas International Airport), São Paulo - SP, Guarulhos - GUA (SP International Airport), São José dos Campos - SJC, Volta Redonda - VR, Rio de Janeiro- RJ and Galeão - GA(RJ International Airport).

\subsection{The Brazilian HSR line project - input data set}

The data set used in this research was obtained by the report published by the Consortium Halcrow - Sinergia (HalcrowSinergia Consortium, July 2009). This consortium was hired by the Inter American Development Bank (Iadb) and the Brazilian National Bank for the Economics and Social Development (BNDES) to evaluate the feasibility of the Brazilian HSR line project. Table 1 presents the projected initial demand and the distances, in parentheses, for each OD pair. 
The Variation of the costs and the demand for this work assume, at first, a yearly drift of $5 \%(\mu)$ and a yearly volatility of $2.5 \%(\sigma)$ when applying Eq. 1. Afterwards, analysis are also made assuming yearly drifts of $10 \%$ and $2 \%$ with corresponding yearly volatilities of $5 \%$ and $1 \%$. Therefore, similar curves to the ones presented in Fig. 2 are obtained for each OD pair given in Table 1. It is observed that the highest demands are for the OD pairs where the cities are either industrial or have a very high population (Campinas, São Paulo, São José dos Campos and Rio de Janeiro), as it should be:.

Table 1 - Demand and Distance in kilometers for the OD pairs - Brazilian case study.

\begin{tabular}{c|c|c|c|c|c|c|c|c}
\hline \multirow{2}{*}{} & \multicolumn{7}{|c}{ ORIGINA DEMAND - 2014(PASSENGER THOUSAND) AND DISTANCE (KM.) } \\
\cline { 2 - 9 } & RJ & GA. & VR & SJC & GUA & SP & VIR. & CAM. \\
\hline RJ & $0(0)$ & $688(15)$ & $1,31(118)$ & $106(329)$ & $0(390)$ & $3,22(412)$ & $0(488)$ & $318(511)$ \\
\hline GA & $688(15)$ & $0(0)$ & $52(103)$ & $0(314)$ & $0(375)$ & $0(397)$ & $0(472)$ & $0(496)$ \\
\hline VR & $1,31(118)$ & $52(103)$ & $0(0)$ & $127(210)$ & $0(272)$ & $92(294)$ & $0(369)$ & $20(392)$ \\
\hline SJC & $107(329)$ & $0(314)$ & $127(210)$ & $0(0)$ & $80(62)$ & $4,28(84)$ & $0(159)$ & $653(182)$ \\
\hline GUA & $0(390.4)$ & $0(376)$ & $0(272)$ & $80(62)$ & $0(0)$ & $0(22)$ & $0(97)$ & $177(120)$ \\
\hline SP & $3,22(412)$ & $0(397)$ & $92(294)$ & $4,28(84)$ & $0(22)$ & $0(0)$ & $0(75)$ & $6,19(99)$ \\
\hline VIR. & $0(488)$ & $0(472)$ & $0(369)$ & $0(159)$ & $0(97)$ & $0(75)$ & $0(0)$ & $207(23)$ \\
\hline CAM. & $318(511)$ & $0(496)$ & $20(392)$ & $653(182)$ & $177(120)$ & $6,19(99)$ & $207(23)$ & $0(0)$ \\
\hline
\end{tabular}

The differing point for the 2 cases considered in this research are related to the costs and the overestimation of the demand when building the High Speed Rail (HSR) line: US\$ 17 billion and 80\% called Case 1 and, US\$ 25 billion and $90 \%$ called Case 2. For each case, the model has been applied assuming randomness or not for the demand besides considering that it can be either overestimated or not.

\subsection{The Brazilian HSR line project - feasibility results.}

This section presents the results obtained for the 2 cases studied of the Brazilian HSR project. The case study 1 assumes that the cost for this infrastructure project will be US\$ 17 billion and its results are given in Table 2 .

Analyzing the results for the case 1, for the lowest fare of US\$ 0,125 cents/kil., the project will never be a viable one independent if the demand is random or overestimated. This result is quite an important one, once the initial demand was evaluated assuming that this lowest fare would be the charged one for the OD pairs. Moreover, the one way trip for the OD pair RJ-SP (Rio de Janeiro - São Paulo), for instance, will be US\$130 with this lowest fare, a quite high fare when compared with the air fare already charged for this same OD pair.

Analyzing the results for the case 2 presented also in table 2, it can be observed that for the lowest fare, US $\$ 0,125$ cents/kil, the project will never be also a viable one. Obviously, the obtained results are quite worse than the ones presented for case 1 , since the cost to build the HSR line is almost $50 \%$ higher, even though the demand has been considered to be overestimated by just $10 \%$, as the real demand is $90 \%$ of the initial demand for case 2 . The best return for this case is US\$ 12 billion, for a 40 year project, but this return can be considered quite low, due not only to the time frame of the project but also to its construction cost and to all its risks involved. The model works quite well when comparing the two cases because, for example, when the demand is neither random nor overestimated, the profit decreases by US\$ 8 billion, due to the higher construction cost increasing from US\$ 17 billion to US\$ 25 billion.

The results shown in table 3 consider the cases when the demand is random and overestimated but assuming growth rates of $2 \%$ or $10 \%$ with volatilities rates of $1 \%$ or $5 \%$, respectively. Analyzing Table 3 , when the cost is the lowest one, US\$ 17 billion having the lowest growth rate of $2 \%$ and with the highest fare being charged, US\$ 0.25 cents/kil., the project will have a debt of US\$ 8.1 billion. When the cost is the highest one, US\$ 25 billion, with the lowest fare being charged of US\$ 0.125 cents/kil., the project will be profitable by about US $\$ 30.4$ billion for the case with the highest growth rate, $10 \%$. Certainly, the results in table 3 with drifts of $10 \%$ are not very realistic ones, due the very high growth rate of $10 \%$ assumed for the demand for every year.

Unfortunately, the Brazilian Government is suggesting also that there will be an up-front payment to the Government of up to US\$ 15 billion by the winning consortium. Therefore, the total cost of the HSR line project would go up to US\$ 32 billion for the case study 1 or, US\$ 40 billion for the case study 2, and that could offset any attractiveness for the Brazilian HSR line project. All the presented results were obtained running the data set on a PC with a Core i7 processor and 8 Giga of RAM at $1.80 \mathrm{GHz}$, and the computer time for 1,000 runs of the simulation was about 2 minutes for each case. 
Table 2 - Cases 1 and 2 - Cost to build the HSR line: US\$ 17 billion, and US\$ 25 billion, respectively with $\mu=5 \%$ and $\sigma=2.5 \%$.

\begin{tabular}{|c|c|c|c|c|}
\hline \multicolumn{5}{|c|}{$\begin{array}{l}\text { Case } 1 \text { - Net Present Value (NPV) - Billions of Dollars } \\
\text { (a ssumed construction cost: U SS } 17 \text { billion). }\end{array}$} \\
\hline \multicolumn{2}{|r|}{ Dem and } & \multicolumn{3}{|c|}{$\begin{array}{c}\text { F are/kilom eter (USS } \\
\text { cents/kil.) }\end{array}$} \\
\hline Random & Overestimated $(0.80)$ & 0.125 & 0.2 & 0.25 \\
\hline 0 & 0 & -10.3 & 7.9 & 20.0 \\
\hline 1 & 1 & -16.3 & -1.8 & 7.8 \\
\hline \multicolumn{5}{|c|}{$\begin{array}{l}\text { Case } 2 \text { - Net Present Value (NPV) - Billions of Dollars } \\
\text { (a ssumed con struction cost: U SS } 25 \text { billion). }\end{array}$} \\
\hline \multicolumn{2}{|r|}{ Dem and } & \multicolumn{3}{|c|}{$\begin{array}{c}\text { F are/kilometer (USS } \\
\text { cents/kil.) }\end{array}$} \\
\hline Random & Overestim ated $(0.90)$ & 0.125 & 0.2 & 0.25 \\
\hline 0 & 0 & -18.3 & $-0,08$ & 12.0 \\
\hline 1 & 1 & -21.3 & $-4,9$ & 6.1 \\
\hline
\end{tabular}

Table 3- Different values for the drift and volatility. Reral demand is $90 \%$ of the initial one.

\begin{tabular}{c|c|c|c}
\hline \multicolumn{4}{c}{ Net Present Value (NPV) - USS Billions, $\mu=2 \%$ and $\sigma=1 \%$. } \\
\hline \multirow{2}{*}{ Assumed Cost (USS billion) } & \multicolumn{3}{|c}{ Fare/kilom eter (USS cents/kil.) } \\
\cline { 2 - 4 } & 0.125 & 0.2 & 0.25 \\
\hline 17 & -24.3 & -14.6 & -8.1 \\
\hline \hline 25 & -32.2 & -22.6 & -16.1 \\
\hline \hline \multicolumn{4}{|c}{ Fare/kilom eter (USS cents/kil.) } \\
\hline \multirow{2}{*}{ Nssumed Cost (USS billion) } & 0.125 & 0.2 & 0.25 \\
\hline 17 & 38.3 & 85.7 & 117.4 \\
\hline \hline 25 & 30.4 & 77.6 & 109.2 \\
\hline \hline
\end{tabular}

\section{Conclusion}

A model to determine the feasibility to build a High Speed Rail (HSR) line has been developed and applied to the Brazilian case. The HSR model considered the case where the demand can be random and overestimated.

When the demand is considered random and overestimated by about $80 \%$, and if the cost to build the rail line is the one considered by the Brazilian Federal Government, US\$ 17 billion, the project will not be a feasible one if the charged fare is US\$ 0.125 cents/kil.. It is an important result because the project will probably cost more than US\$ 17 billion, and with this fare, a one way trip for the OD pair RJ-SP (Rio de Janeiro - São Paulo) will be about US\$130, a quite high fare when compared with the air trip fare already being charged for this same OD pair.

The model can be extended in a number of ways like considering different rates of growth for different periods of time, for instance. Nevertheless, its robustness resides in the fact that either the revenues or the costs involved have stochastic properties.

It can be concluded that a very expensive project such as a new HSR line project must be carefully analyzed, before deciding to start its construction. The transportation system can have other priorities to be previously solved, before making such a high expensive project to become a reality.

\section{References}

Banister, D. and Givoni, M. (2006) Airline and Railway integration, Transport Policy 13(4): 386-297.

Barrón de Angoiti, I. (2004): Construction costs of high speed lines. UIC, París.

Brownstone, D., Hansen, M and Madanat, S., (June 2010) Review of "Bay Area/California High_Speed Rail Ridership and Revenue Forecasting Study, ITS, University of California at Berkeley, Berkeley, CA, USA.

de Rus, G. (2012) The Economic Effects of High Speed rail Investment, Discussion paper No. 2008-16 - Revised May 2012, University pf Las Palmas, Spain.

European Commission (2001a), 'Revitalizing the railways' (European Commission, Whitev Paper. Brussels, Belgium.

Gramlich,E.M.(1994) Infrastructure Investment:A review Essay, Journal of Economic Literature,vol. 32,n.3,pp.1176-1196.

Halcrow-Sinergia Consortium (July 2009) HSR Brazilian Project, Sinergia Estudos e Projeto Lmtd and Halcrow vols. 1-6 (in portuguese).

Hull, J. (2005). In: Options, 'Futures and Other Derivatives sixth ed. Prentice Hall, Upper Saddle River, NJ.

Sichelschmidt, H. (1999), The EU programme "trans-European networks"- critical assessment, Transport Policy, 6 (3), pp. 169-181

Vickerman, R. (1997) High Speed rail in Europe: Experience and issues for future development, The Annals of Regional Science, vol. 21, pp. 21-38. 